\title{
TaXa21, a Leucine-Rich Repeat Receptor-Like Kinase Gene Associated with TaWRKY76 and TaWRKY62, Plays Positive Roles in Wheat High-Temperature Seedling Plant Resistance to Puccinia striiformis f. sp. tritici
}

\author{
Jiahui Wang, ${ }^{1}$ Junjuan Wang, ${ }^{1}$ Hongsheng Shang, ${ }^{1}$ Xianming Chen, ${ }^{2}$ Xiangming $X u,{ }^{3}$ and \\ Xiaoping $\mathrm{Hu}^{1,+}$ \\ ${ }^{1}$ State Key Laboratory of Crop Stress Biology for Arid Areas and College of Plant Protection, Northwest A\&F University, \\ Taicheng Road 3, Yangling, Shaanxi 712100, China \\ ${ }^{2}$ Agricultural Research Service, United States Department of Agriculture and Department of Plant Pathology, Washington State \\ University, Pullman, WA 99164-6430, U.S.A. \\ ${ }^{3}$ NIAB East Malling Research, New Road, East Malling, ME19 6BJ, Kent, U.K. \\ Accepted 18 June 2019.
}

Puccinia striiformis f. sp. tritici causes wheat stripe rust, one of most important diseases of wheat worldwide. Hightemperature seedling plant (HTSP) resistance of wheat to $P$. striiformis f. sp. tritici is one specific type of host resistance, induced by high temperature (HT). Receptor-like kinases (RLKs) play key roles in regulating plant development and signaling networks, but there have been no reports on possible roles played by RLKs in wheat HTSP to $P$. striiformis f. sp. tritici. In the present study, a leucine rich repeat (LRR)-RLK gene, $\mathrm{TaXa21}$, with a high homology with rice bacterial blight resistance gene $\mathrm{Xa21}$, was cloned from wheat cultivar Xiaoyan 6 (XY 6). TaXa21 expression was up-regulated by the exposure to HT $\left(20^{\circ} \mathrm{C}\right)$ for $24 \mathrm{~h}$ at 8 days postinoculation with $P$. striiformis f. sp. tritici and was induced by ethylene (ET) and hydrogen peroxide $\left(\mathrm{H}_{2} \mathrm{O}_{2}\right)$. Knocking down TaXa21 using virus-induced gene silencing reduced HTSP resistance to $P$. striiformis f. sp. tritici compared with the control plants. In addition, the expression level of $\mathrm{TaCAT}$ in the $\mathrm{H}_{2} \mathrm{O}_{2}$ pathway was induced and $\mathrm{TaACO}$ in the ET signal pathway was reduced in the HT-treated $\mathrm{TaXa21}$-silenced plants. Transient expression of TaXa21 in tobacco leaves confirmed its subcellular localization in plasma membrane, consistent with the prediction from bioinformatics analysis. The transmembrane and kinase domain of TaXa21 can interact with TaWRKY76 in the nucleus and cell membrane, which is different from the localization of Xa21 in rice. The interaction between TaWRKY76 and TaWRKY62 (positively involved in the HTSP resistance of XY

\section{${ }^{\dagger}$ Corresponding author: X. Hu; xphu@nwsuaf.edu.cn}

Funding: This work was supported by grants from the National Key Research and Development Program of China (grant number 2018YFD0200402, 2016YFD0300702), the National Natural Science Foundation of China (grant number 31271985) and the Open Project Program of State Key Laboratory of Crop Stress Biology for Arid Areas, NWAFU, Yangling, Shaanxi, 712100, China (grant number CSBAAKF2018002).

*The $\boldsymbol{e}$-Xtra logo stands for "electronic extra" and indicates that two supplementary figures and one supplementary table are published online.

The author(s) declare no conflict of interest.

(c) 2019 The American Phytopathological Society
6) were observed. Together, these results indicated that TaXa21 is a RLK associated with TaWRKY76 and TaWRKY62 and functions as a positive regulator of wheat HTSP resistance to $P$. striiformis f. sp. tritici. Furthermore, the host defense is mediated by the $\mathrm{H}_{2} \mathrm{O}_{2}$ and ET signal pathways.

Keywords: high-temperature seedling plant resistance, stripe rust, TaXa21, TaWRKY76, TaWRKY62, interaction

Stripe rust, caused by Puccinia striiformis f. sp. tritici, is one of the most devastating fungal diseases of wheat worldwide (Chen 2005). Breeding resistant cultivars is the most cost-effective and environment-friendly approach to control $P$. striiformis f. sp. tritici (Chen 2007; Chen and Line 1995; Sui et al. 2009; Zhang et al. 2001). However, wheat resistance to $P$. striiformis f. sp. tritici is frequently overcome by the pathogen (Peng et al. 1999).

High-temperature (HT) resistance of wheat to P. striiformis $\mathrm{f}$. sp. tritici is induced by exposure of wheat plants to HT. Based on the growth stage, HT resistance can be divided into two types, high-temperature seedling plant (HTSP) resistance and high-temperature adult-plant (HTAP) resistance (Chen 2013). Wheat plants with HTAP resistance are susceptible to $P$. striiformis $\mathrm{f}$. $\mathrm{sp}$. tritici in the seedling stage but become resistant in the adult stage under HT (Chen et al. 2013). In contrast, the HTSP resistance is expressed throughout the entire wheat growth period when seedlings were exposed to $20^{\circ} \mathrm{C}$ only for $24 \mathrm{~h}$ during the initial $P$. striiformis f. sp. tritici incubation stage (Ma and Shang 2000; Tao et al. 2018). Compared with the HTAP resistance to $P$. striiformis f. sp. tritici, there have been fewer studies on the mechanisms of the HTSP resistance to $P$. striiformis f. sp. tritici. Xiaoyan 6 (XY 6) is a wheat cultivar exhibiting the typical HTSP resistance to P. striiformis f. sp. tritici; XY 6 has maintained the HTSP resistance against $P$. striiformis $\mathrm{f}$. sp. tritici under field conditions for more than 30 years (Ma and Shang 2000) and is still grown commercially in China.

Receptor-like kinases (RLKs), one of the largest protein families, with at least 600 members, can induce pathogenassociated molecular pattern (PAMP)-triggered immunity (PTI) or effector-triggered immunity (ETI) plant defense responses against pathogens (Shiu and Bleecker 2001). A typical RLK 
contains a ligand-binding domain, a transmembrane (TM) domain, and an intracellular kinase domain (Shiu and Bleecker 2001). The extracellular domain of RLK binds specific ligands of pathogens, and the intracellular kinase domain transduces signals to downstream components by phosphorylation, activating the defense response (Morillo and Tax 2006; Osakabe et al. 2013). RLKs can be divided into more than 44 subfamilies, depending on the variation of the extracellular domain (Dardick et al. 2012; Gish and Clark 2011). The leucine-rich repeat (LRR)-RLK, the largest subclass of RLKs, with 235 members in Arabidopsis and 309 members in rice, plays important roles in mediating plant responses to organ growth, environmental cues, and hormone and stress perception (Afzal et al. 2008; Kim and Wang 2010; Kinoshita et al. 2010; Shpak et al. 2005). In addition, some LRR-RLKs may also be involved in regulating plant responses to biotic stresses, including $F L S 2$, EFR, and Xa21 (Antolín-Llovera et al. 2012; Bauer et al. 2001; Shiu and Bleecker 2001). FLS2, a well-studied plant pattern-recognition receptor (PRR), perceives and binds bacterial flagellin (flg22), resulting in the signal transduction to intracellular and amplification by the mitogen-activated protein kinase cascade response with the phosphorylation of intracellular kinases, and WRKY22 and WRKY29 act in the downstream of $F L S 2$ to activate defense-related genes (Tang et al. 2017). EFR, a cell-surface receptor-like kinase of Arabidopsis thaliana, recognizes an epitope (elf18) of bacteria, activating plant defense responses (Schoonbeek et al. 2015; Zipfel et al. 2006). Xa21, encoding a TM receptor kinase, is the first bacterial blight resistance gene cloned from rice and has received much attention because of its broad-spectrum resistance against Xanthomonas oryzae pv. oryzae (Peng et al. 2008; Pruitt et al. 2015). Recent studies showed that OsWRKY62 could interact with the intracellular domain of $\mathrm{Xa} 21$ in the rice protoplast nucleus. Therefore, a new possible immune receptor model was proposed, i.e., a kinase is transferred into the nucleus and interacts with a transcriptional regulator directly after the receptor has recognized conserved microbial signatures (Peng et al. 2008).

In the present study, we identified and cloned a homolog of the rice $X a 21$ in wheat, named $T a X a 21$, which was significantly up-regulated in the HTSP resistance of XY 6 to P. striiformis $\mathrm{f}$. sp. tritici and shared 59\% similarity in amino acids with the rice $X a 21$. The transcript profile of TaXa21 was analyzed under different hormone treatments and its subcellular localization was determined. Additionally, interactions between partial domains of TaXa21 and TaWRKY62 and, also, of TaWRKY76 and TaWRKY62 were studied. To confirm whether TaXa21 participates in HTSP resistance to $P$. striiformis f. sp. tritici, knockdown of TaXa21 by virus induced gene silencing (VIGS) was performed to study subsequent host resistance against $P$. striiformis f. sp. tritici. Our results suggest that TaXa21 is associated with TaWRKY76 and TaWRKY62 and involved in HTSP resistance to $P$. striiformis f. sp. tritici.

\section{RESULTS}

\section{Cloning and sequence characterization of $\mathrm{TaXa21.}$}

Based on the transcriptome sequencing data, a 3,464-bp cDNA fragment was isolated from XY 6, using rapid amplification of cDNA ends (RACE). This gene encodes a 1,051amino acid protein with an estimated molecular mass of $113.39 \mathrm{kDa}$ and an isoelectric point (PI value) of 7.7. The protein is predicted to possess a signal-peptide domain, nine LRR domains, a TM domain, and a serine/threonine protein kinase catalytic domain, consistent with structural features of RLKs (Supplementary Fig. S1). Nucleic acid sequence analysis indicated that this protein shares $56 \%$ similarity in amino acids with the rice $X a 21$. Therefore, we designated this gene as TaXa21 (GenBank accession number MH891497). TaXa21 shares $99.97 \%$ similarity in nucleotides with TaXa21-4BL in the IWGSC wheat genome database (Supplementary Fig. S2).

\section{Expression of $\mathrm{TaXa21}$ in different tissues and in response} to hormones and hydrogen peroxide.

TaXa21 expression in roots, stems, and leaves of XY 6 under normal conditions was quantified by quantitative reverse transcription (qRT)-PCR. The expression of TaXa21 varied greatly with tissues in XY 6. The expression level in leaves was 5.3fold and 12.5-fold of that in roots and stems, respectively (Fig. 1A).

To study the TaXa21 expression patterns in response to different plant hormones, wheat leaves were treated with four hormones: salicylic acid (SA), abscisic acid (ABA), methyl jasmonate (MeJA), and ethanol (ET). Relative to expression at $0 \mathrm{~h}$ of each treament, the transcript of TaXa2l increased by 5.2fold after ET treatment for $0.5 \mathrm{~h}$. Both ABA (for $2 \mathrm{~h}$ ) and JA (for $0.5 \mathrm{~h}$ ) treatments reduced the expression of TaXa21, but the SA treatment did not affect TaXa21 expression (Fig. 1B). In addition, the TaXa21 expression level was significantly induced by hydrogen peroxide $\left(\mathrm{H}_{2} \mathrm{O}_{2}\right)$ at $2 \mathrm{~h}$, with an approximate 6.5 fold increase.

\section{Expression of $\mathrm{TaXa21}$ in HTSP resistance to $P$. striiformis f. sp. tritici.}

To analyze $\mathrm{TaXa} 21$ transcript profiles in HTSP resistance to P. striiformis f. sp. tritici, TaXa21 expression was measured in leaf samples collected at 0 to $312 \mathrm{~h}$ postinoculation (hpi) with P. striiformis f. sp. tritici. As shown in Figure 2, the transcript levels of TaXa21 in inoculated leaves were higher than in noninoculated leaves in the early stage of $P$. striiformis $\mathrm{f}$. $\mathrm{sp}$. tritici infection. After exposure to HT $\left(20^{\circ} \mathrm{C}\right)$ at $192 \mathrm{hpi}$ for 24 $\mathrm{h}$, the expression of TaXa21 in the HT samples was significantly higher at 204 and 216 hpi than in the normal temperature $\left(\mathrm{NT}, 15^{\circ} \mathrm{C}\right)$ samples; the level at $204 \mathrm{hpi}$ was approximately 12 fold higher than the base level. The transcript level of TaXa21 did not significantly differ between the HT and NT mock (noninoculated) treatments.

\section{Suppression of $\mathrm{TaXa} 21$ reduces HTSP resistance to $P$. striiformis f. sp. tritici.}

Because TaXa21 was related to the HTSP resistance to $P$. striiformis f. sp. tritici, we studied the effects of knocking down TaXa21 on host response and P. striiformis f. sp. tritici development. Knocking down was achieved through barley stripe mosaic virus (BSMV)-based VIGS. The 3' terminal 151bp specific segment of TaXa21 was inserted to BSMV: $\gamma$ vector, designed as BSMV:TaXa21-as. Stripe mosaic symptoms were observed nine to 10 days after BSMV inoculation (Fig. 3A); the expression level of TaXa21 was suppressed by 59 to $72 \%$ (Fig. 3d). Next, the fourth leaves of BSMV-inoculated seedlings were inoculated with $P$. striiformis f. sp. tritici race CYR32, and stripe rust symptoms and signs were assessed at 15 days postinoculation (dpi) with P. striiformis f. sp. tritici. XY 6 showed a susceptible response under the continuous NT (Fig. 3B), whereas, in seedlings exposed to HT for $24 \mathrm{~h}$, uredia on the TaXa21-silenced leaves were more than those of nonsilenced leaves, which were then inoculated with BSMV:00 under HT as a control (Fig. 3C). Consistent with the phenotype, qRT-PCR analysis showed that the transcript level of $T a X a 21$ was upregulated after the HT treatment for $12 \mathrm{~h}$ in those nonsilenced leaves. Although TaXa21 can be induced again by the HT treatment in the silenced leaves, the expression level was lower than that in the HT-treated nonsilenced plants at 24, 72, and $120 \mathrm{~h}$ post-temperature treatment (hptt) (Fig. 3E). 
To determine whether the expression level of $P$. striiformis $\mathrm{f}$. sp. tritici resistance-related genes in TaXa21 knockdown leaves was affected, TaACO (ET pathway) and TaCAT $\left(\mathrm{H}_{2} \mathrm{O}_{2}\right.$ pathway) were quantified with qRT-PCR. The TaACO transcript level was significantly higher in the HT-treated nonsilenced leaves than in the HT-treated $\mathrm{TaXa21}$-silenced leaves at both 12 and 24 hpi (Fig. 3F). In contrast, the TaCAT transcript level was higher in the TaXa21-silenced leaves than in nonsilenced leaves at 48, 72, and $120 \mathrm{hpi}$; the highest level was in the NT-treated TaXa21-silenced plants (Fig. 3G).

\section{Observation of $\boldsymbol{P}$. striiformis f. sp. tritici growth and host response.}

TaXa21-silenced XY 6 leaves were assessed microscopically at 48 and 120 hpi to determine hyphal length and number of haustorial mother cells (Fig. 4A to D). There were no obvious differences in the hyphal length and the number of haustorial mother cells at 48 and 120 hpi between the TaXa21 knockdown plants and BSMV:00 control plants (Fig. 4E and F).

Pathogen development and host response were assessed microscopically in wheat leaves with different temperature treatments (Fig. 5A and B). Colony length in the HT-treated TaXa21-silenced leaves significantly decreased compared with the NT-treated TaXa21-silenced at 24 hptt (Fig. 5D). A large number of uredinia were observed at $120 \mathrm{hptt}$; the uredinium length was significantly shorter in the HT-treated TaXa21knockdown leaves than in the NT-treated TaXa21-knockdown leaves (Fig. 5C). In addition, there were fewer necrotic cells in the TaXa21-knockdown leaves than in the control leaves at 48 and 120 hptt (Fig. 5E).

\section{Subcellular location of TaXa21-GFP fusion protein.}

The predicted $\mathrm{TaXa} 21$ protein sequence contains an extracellular receptor domain, a single TM domain, and a C-terminal cytoplasmic serine/threonine protein kinase domain, indicating that TaXa21 could be a plasma membrane protein. To confirm this inference, the fusion construct pCambia1302:TaXa21-GFP and the control vector pCambia1302:GFP were transformed into tobacco (Nicotiana benthamiana) cells. When TaXa21GFP fusion protein was expressed in the tobacco cells through agrobacterium-mediated transformation, adding proteasome inhibitor MG132 led to accumulation of TaXa21 protein (Fig. $6 \mathrm{~A}$ ), indicating that $\mathrm{TaXa} 21$ protein was degraded by the ubiquitin-proteinase pathway. Green fluorescent protein (GFP) was diffusely distributed throughout the host cells, while green fluorescence produced by the TaXa21-GFP and red fluorescence produced by the AtPIP2A-mcherry protein overlapped in the plasma membrane with MG132, showing that TaXa21 is located in plasma membrane (Fig. 6B).

\section{Interactions among TaXa21, TaWRKY76, and TaWRKY62.}

To determine whether interactions between TaXa21 and TaWRKY76 and between TaXa21 and TaWRKY62 occur and are involved in the host defense response, yeast two-hybrid was performed. We noticed that BD-TaWRKY76 exhibited a weak autoactivation activity, which was abolished by adding $10 \mathrm{mM}$ 3-amino-1, 2, 4-triazole (3AT). A truncated TaXa21, carrying a TM domain and a kinase domain, was fused with bait vector pGBKT7, and TaWRKY76 and TaWRKY62 were fused with prey vector pGADT7. Interaction was observed between
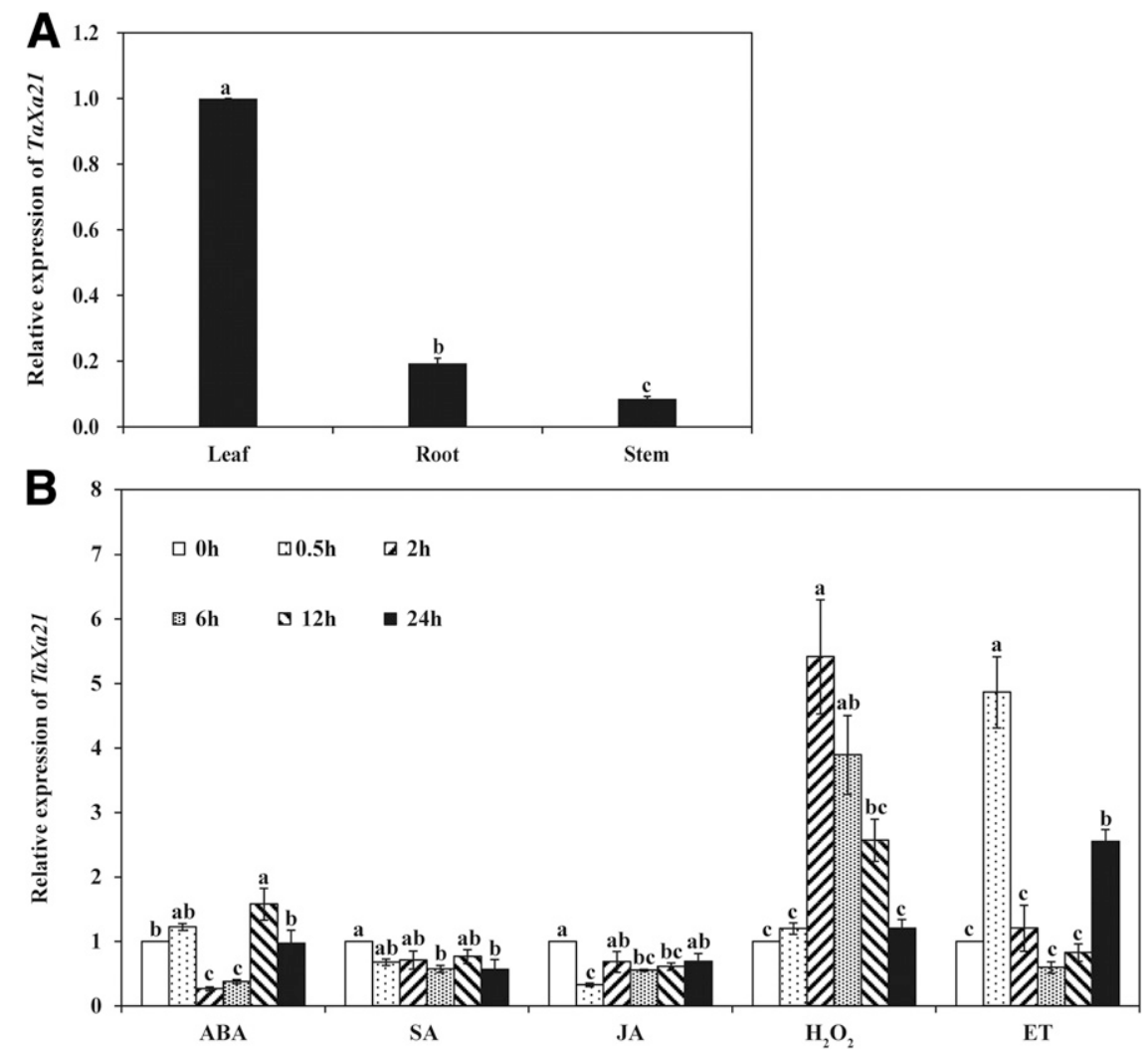

Fig. 1. Expression pattern of TaXa21 in wheat cultivar Xiaoyan 6 leaves as quantified by quantitative reverse transcription (qRT)-PCR. A, Transcript level of $T a X a 21$ in the leaf, stem, and root issues. B, Transcript profiles of TaXa21 after hormone and $\mathrm{H}_{2} \mathrm{O}_{2}$ treatments. The transcriptional level was determined by qRT-PCR with Ta26s as a reference gene. Hormone elicitors: ABA, abscisic acid; SA, salicylic acid; MeJA, methyl jasmonate; ET, ethylene. $\mathrm{H}_{2} \mathrm{O}_{2}$, hydrogen peroxide. The mock control was treated with $0.1 \%$ (vol/vol) ethanol solution. The expression level of TaXa21 at $0 \mathrm{~h}$ was normalized as 1 for each treatment. Analysis of variance was followed by the Duncan's multiple comparison test. The error bar represents the standard errors (three replicates). Duncan's multiple comparison test was conducted at the different timepoints within each treatment; TaXa21 expression levels do not differ significantly if they contain at least one common lowercase letter between timepoints for each treatment. 
BD-TaXa21-F1 and AD-TaWRKY76, indicated by the yeast growth on the synthetic dropout (SD) medium lacking Leu, Trp, and His supplemented with $10 \mathrm{mM} 3 \mathrm{AT}$. No interactions were detected between TaXa21-F1 and TaWRKY62 (data not shown). To determine whether the TM domain of TaXa21 is essential for its interaction with TaWRKY76, only the kinase domain of TaXa21 was fused with pGBKT7 and transformed together with the AD-TaWRKY76 into AH109 yeast competent cells. No yeast growth was observed, suggesting that the interaction between TaXa21 and TaWRKY76 requires the TM domain. In addition, we also confirmed that TaWRKY76 could interact with TaWRKY62 in the yeast (Fig. 7B).

To validate whether TaXa21 interacts with TaWRKY76 in planta, different regions of $\mathrm{TaXa} 21$, were fused with the $\mathrm{C}$ terminal fragment of the yellow fluorescent protein $\left(\mathrm{YFP}^{\mathrm{C}}\right)$; and TaWRKY76 and TaWRKY62 were fused with a Nterminal fragment of the yellow fluorescent protein $\left(\mathrm{YFP}^{\mathrm{N}}\right)$. Fluorescence was predominantly detected in nuclei and cell membranes when TaXa21-F1-YFP ${ }^{\mathrm{C}}$ and TaWRKY76-YFP ${ }^{\mathrm{N}}$ were expressed transiently in tobacco (Fig. 7C). These results indicated that the TM and kinase domains of TaXa21 could interact with full-length TaWRKY76 in nuclei and cell membranes. Meanwhile, the interaction between full-length TaWRKY76 and TaWRKY62 in nuclei was observed.

To determine whether TaWRKY76 and TaWRKY62 are localized in nuclei or enter nuclei from cytoplasma after interactions with other proteins, we conducted subcellular localization experiments in tobacco cells. Green fluorescence produced by the TaWRKY76-GFP and TaWRKY62-GFP (Fig. 7D) fusion protein and red fluorescence produced by the $\mathrm{AtH}_{2} \mathrm{~B}$-mcherry protein overlapped in nuclei, indicating a nuclear localization of TaWRKY76 and TaWRKY62.

\section{DISCUSSION}

Plants can be infected by various pathogens and specific host defense mechanisms have been evolved to cope with these pathogens. Plants recognize PAMPs by PRRs, resulting in PTI responses (Rodriguez et al. 2010). To suppress PTI, pathogens produce specific pathogen proteins called effectors. Plants can also recognize effectors by specific resistance $(R)$ genes, leading to ETI responses (Chisholm et al. 2006). Accumulating evidences indicate that LRR-RLKs play important roles in the signaling pathway in the host-pathogen interactions.

In the present study, we determined that $T a X a 21$ is a LRRRLK and involved in HTSP resistance to $P$. striiformis f. sp. tritici in wheat. The transcription level of TaXa21 increased after the HT treatment and downregulation of TaXa21 expression compromised the HTSP resistance to $P$. striiformis $\mathrm{f}$. $\mathrm{sp}$. tritici, indicating that $T a X a 21$ functions as a positive regulator of the HTSP resistance to $P$. striiformis f. sp. tritici. The TaXa2I expression in the HT-treated leaves was higher than in the HT mock and NT treatments $12 \mathrm{hptt}$, which was earlier than TaWRKY70 (24 hptt). Therefore, we speculate that TaXa21 is located upstream of the signaling pathway and is responsible for perceiving environmental signals and transmitting them downstream such as to WRKY transcription factors. Further research is needed to determine whether TaXa21 in HTSP resistance to $P$. striiformis f. sp. tritici causes PTI or ETI responses.

Numerous studies have demonstrated that transcriptional levels of many LRR-RLKs change upon various exogenous hormone treatments (Chae et al. 2009; ten Hove et al. 2011). In the current study, TaXa21 was down-regulated in response to ABA and JA but induced by ET. Moreover, a key enzyme, $T a A C O$, in the ET biosynthesis pathway was significantly reduced in TaXa21-knockdown HT-treated plants at 12 and 24 hptt, indicating that TaXa21 is involved in the ET-mediated HTSP resistance to $P$. striiformis f. sp. tritici. These results suggest that TaXa21 functions at the nexus of biotic and abiotic stress signals.

Signal transduction through the interaction between WRKY transcription factors and pathogen sensors is important in host-pathogen interactions. For example, MLA10 in barley, belonging to the coiled coil-nucleo binding-LRR-type of $\mathrm{R}$ proteins, induces ETI against Blumeria graminis f. sp. hordei by interacting with HvWRKY1 and HvWRKY2 in nuclei. Upon B. graminis f. sp. hordei infection, HvWRKY1 and HvWRKY2 can change from transcriptional repressors to transcriptional activators by binding MLA10, resulting in plant defense responses (Shen et al. 2007). In rice, pbl, a panicle blast resistance gene, was reported to interact with OsWRKY45

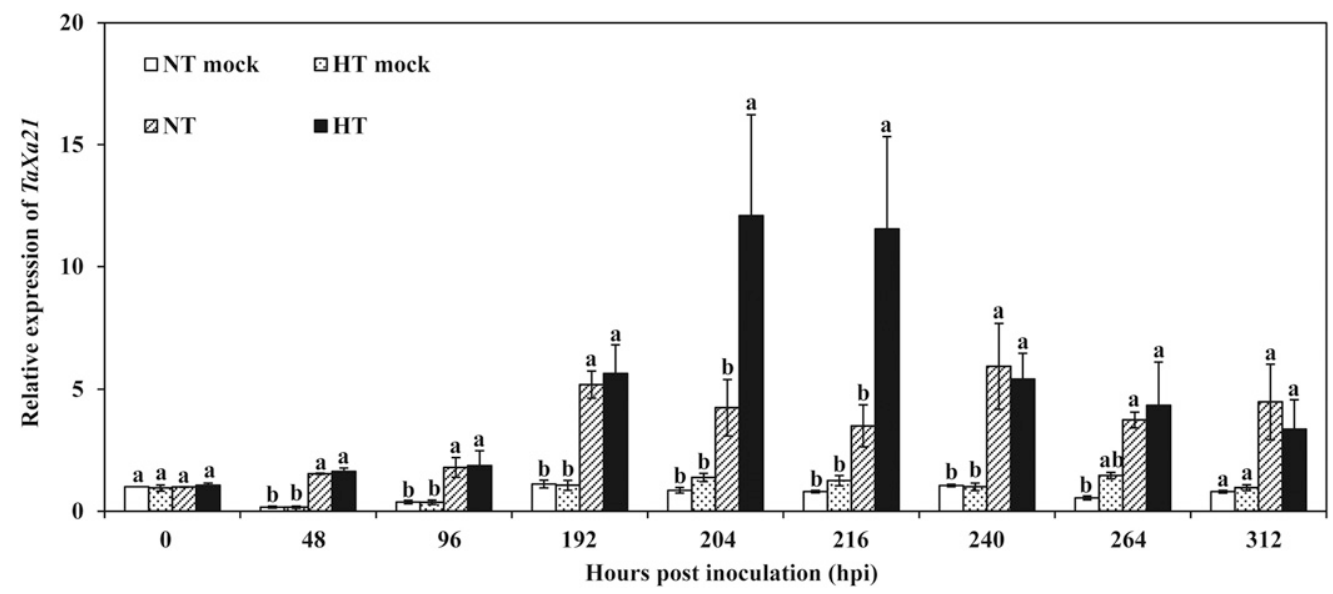

Fig. 2. Quantitative reverse transcription (qRT)-PCR analysis of TaXa21 in response to Puccinia striiformis $\mathrm{f}$. sp. tritici and temperature. NT mock = normal temperature noninoculated leaves under constant temperature $\left(15^{\circ} \mathrm{C}\right)$; HT mock $=$ high-temperature noninoculated leaves with 24 -h exposure to high temperature of $20^{\circ} \mathrm{C} 192 \mathrm{~h}$ postinoculation (hpi) with $P$. striiformis $\mathrm{f}$. sp. tritici (the initial stage of $P$. striiformis $\mathrm{f}$. sp. tritici development); NT $=$ leaves inoculated with $P$. striiformis f. sp. tritici under $15^{\circ} \mathrm{C}$; HT $=$ leaves inoculated with $P$. striformis f. sp. tritici but with $24-\mathrm{h}$ exposure to $20^{\circ} \mathrm{C} 192$ hpi. The transcriptional level was determined by qRT-PCR with Ta26s as a reference gene and was relative to the level at 0 hpi of NT mock for all treatments. The error bar represents the standard errors (three replicates). Duncan's test was conducted among treatments at the same timepoint. There were no significant differences between treatments at the same timepoint sharing at least one lowercase letter. 
in nuclei; and $p b 1$-mediated panicle blast resistance was largely compromised when WRKY45 was knocked down. In addition, wheat wXa21-like1 and wXa21-like2, in which amino acids share 82 and $78 \%$ similarities with TaXa21, can interact with WRKY76 slightly in yeast cells (Cantu et al. 2013). In the present study, we demonstrated that the intact TM and kinase domains of TaXa21 can interact with TaWRKY76 in nuclei and membrane. In addition, TaWRKY76-TaWRKY62 interactions were also observed in nuclei. Previously, we showed that TaWRKY62 positively regulates HTSP resistance to $P$. striiformis f. sp. tritici (Wang et al. 2017b) and that TaWRKY70 plays a positive role in HTSP resistance (Wang et al. 2017a). We also failed to detect any interaction between TaWRKY70 and TaXa21 (data not shown). Based on these results, we
A

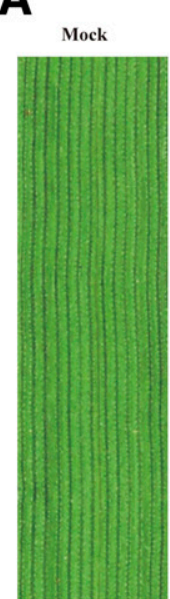

D

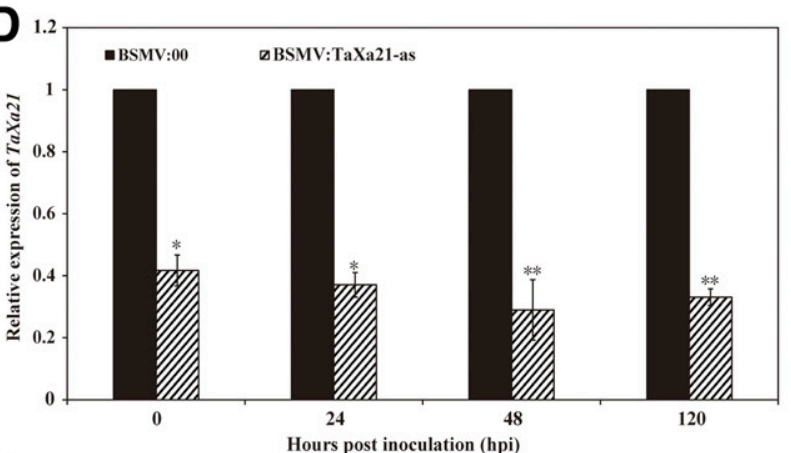

$\mathbf{F}$

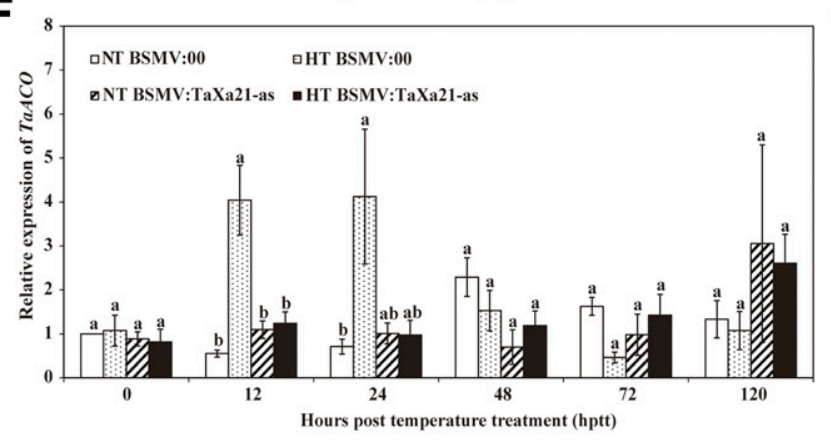

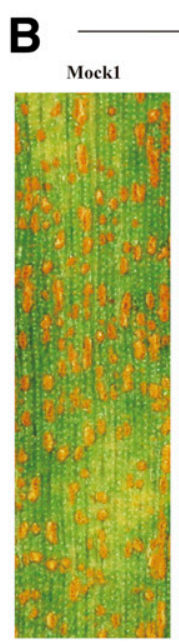

NT
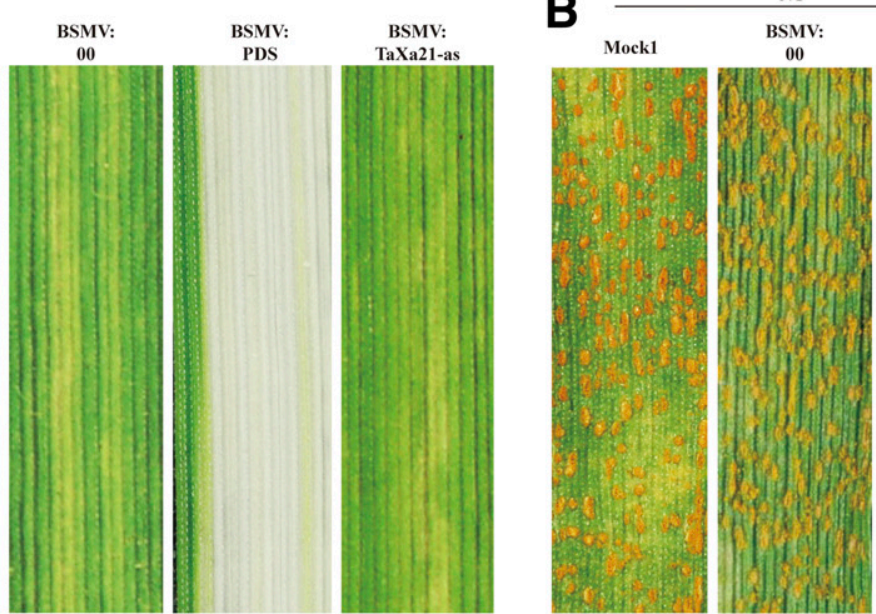

C

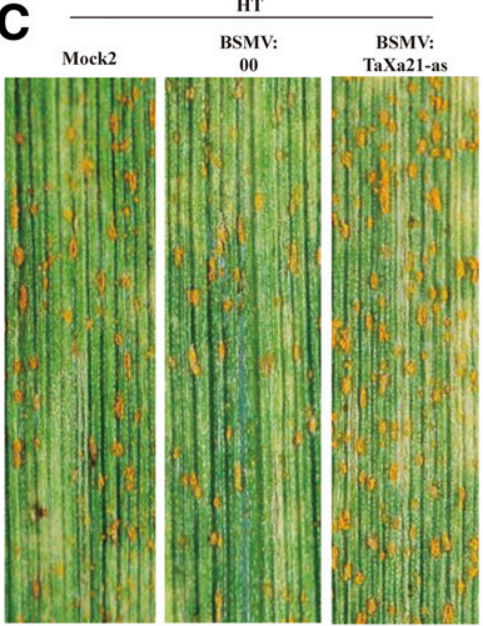

E

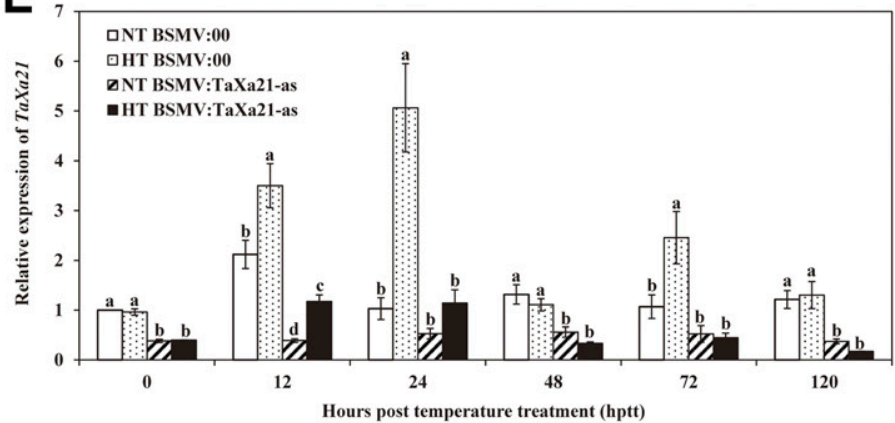

G

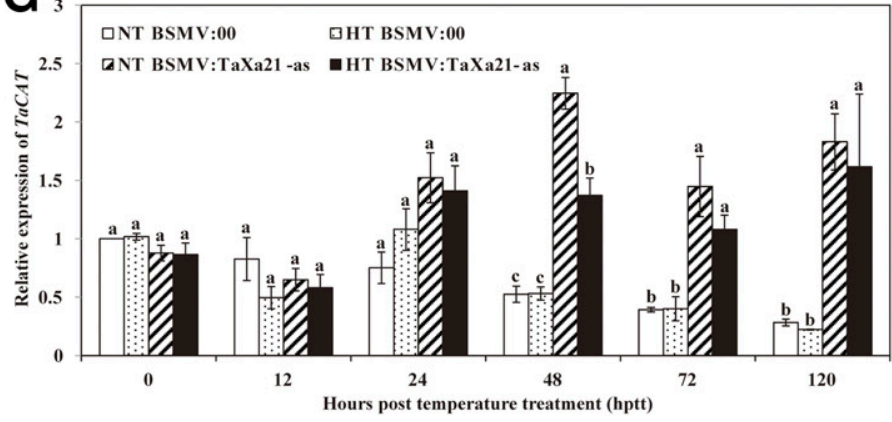

Fig. 3. TaXa21 plays a positive role in the high-temperature seedling plant resistance to Puccinia striiformis f. sp. tritici in wheat cultivar Xiaoyan 6 (XY 6) as indicated by barley stripe mosaic virus (BSMV)-induced silencing. A, Mild chlorotic mosaic and photo-bleaching symptoms on fourth leaves of XY 6 at 9 to 11 days postinoculation with BSMV:00 and BSMV:PDS (phytoene desaturase), respectively. Mock $=$ leaves of XY 6 inoculated with the $1 \times$ FES buffer ( 0.1 M glycine, $0.06 \mathrm{M} \mathrm{K}_{2} \mathrm{HPO}_{4}, 1 \%$ (wt/vol) tetrasodium pyrophosphate, $1 \%$ (wt/vol) bentonite, and 1\% (wt/vol) celite, pH 8.5). B and C, The TaXa21-silenced and nonsilenced leaves were all inoculated with $P$. striiformis f. sp. tritici race CYR32, were transferred to normal temperature (NT) (B) and high temperature (HT) (C) treatments during the $192 \mathrm{~h}$ postinoculation (hpi) (the initial $P$. striiformis $\mathrm{f}$. sp. tritici symptom expression stage), and were assessed at 336 hpi. D, Relative transcript level of TaXa21 in the TaXa21-silenced leaves inoculated with CYR32 under NT. Leaves of XY 6 infected with BSMV:00 or BSMV:TaXa21-as were collected at $0,24,48$, and 120 hpi with CYR32 ( $t$ test, two asterisks (**) indicate $P<0.01$ ). The data were standardized with the Ta26s gene. The transcript level of TaXa21 in the leaves with BSMV:00 at each timepoint was standardized as 1 . E, Transcript abundances of TaXa21 in response to temperature and $P$. striiformis f. sp. tritici inoculation in the TaXa21-silenced and nonsilenced leaves. RNA samples were isolated from wheat leaves preinoculated with BSMV at 0, 12, 24, 48, 72, and $120 \mathrm{~h}$ post-temperature treatment (hptt) after inoculation with CYR32; 0 hptt was the starting time of the HT treatment. F, Transcript analysis of defense-related genes TaACO and G, TaCAT after P. striiformis f. sp. tritici inoculation and temperature treatments in the TaXa21-silenced and nonsilenced leaves. TaCAT = catalase, $T a A C O=1$-aminocyclopropane-1-carboxylate oxidase. The transcriptional level was determined by quantitative reverse transcription-PCR with Ta26s as a reference gene. Treatment comparison was based on the Duncan's multiple range test; standard errors were based on three replicates. The expression levels of TaXa21 (E), TaACO (F), and TaCAT (G) in NT-treated nonsilenced leaves at 0 hptt were standardized as 1 . Duncan's test was conducted among treatments at the same timepoint. There were no significant differences between treatments at the same timepoint if they shared at least one common lowercase letter. 
propose two possible models for the interaction regions of TaXa21 and TaWRKY76. In the first model, upon P. striiformis f. sp. tritici infection and HT treatment, the TM and activated kinase domains of TaXa21 are cleaved from the membrane, move into nuclei, and interact with TaWRKY76; the signal is then further transmitted through the TaWRKY76-TaWRKY62 interaction. In the second model, $P$. striiformis $\mathrm{f}$. sp. tritici inoculation and HT treatment lead to activation of the TaXa21 kinase domain, which phosphorylates TaWRKY76 through their interaction in the cell membrane; the phosphorylated TaWRKY76 proteins are translocated into the nuclei, combine with TaWRKY62, and regulate downstream cascading gene expressions. The evidence to support the second model comes from the Jak-STAT pathway (Darnell et al. 1994). The TM receptor could recognize interferon (IFN), leading to activation of the JAK kinase of receptors and, then, phosphorylation of the STAT protein through the Jak-STAT interaction in the cell membrane. The phosphorylated STAT proteins are translocated to the nuclei, combining with downstream targets and regulate immune responses.

WRKY transcription factors (TFs) contain a DNA-binding domain and can bind to the W-box repeats of promoters in defense-related genes; the interactions between different WRKY TFs alter the activity of sequence-specific DNA binding, leading to varying degrees of plant defense responses. The interaction of WRKY18 with WRKY40 or WRKY60 may have enhanced their DNA-binding activity, which may contribute to their roles in disease resistance (Xu et al. 2006). We previously showed that TaWRKY62 plays a positive role in the HTSP resistance to $P$. striiformis f. sp. tritici in XY 6 (Wang et al. 2017b); the present study confirmed its interaction with TaWRKY76. Further research is needed to determine whether the interaction between TaWRKY76 and TaWRKY62 can change the ability of DNA binding and enhance the defense response.

In summary, we showed differences between homologous gene $\mathrm{Xa} 21$ in rice and $\mathrm{TaXa21}$ in wheat. Unlike the rice Xa21, whose kinase domain could interact with OsWRKY62 in nuclei, the TM and kinase domains of TaXa21 can interact with TaWRKY76 instead of TaWRKY62 in the membrane and nuclei and the intact TM domain is essential for their interaction. Whether these differences are consistent with our two proposed models needs further investigations. TaWRKY62, a positive regulator in HTSP resistance to $P$. striiformis f. sp. tritici, interacts with TaWRKY76 in nuclei. Thus, we speculate that, upon $P$. striiformis f. sp. tritici infection and HT treatment, the extracellular signal is received by the LRR domain of TaXa21 with kinase domain phosphorylation and transmits to TaWRKY62 through TaWRKY76, leading to the ET-mediated defense responses.

\section{MATERIALS AND METHODS}

Plant materials, inoculations, and treatments.

Wheat (Triticum aestivum) cultivar XY 6 and P. striiformis $\mathrm{f}$. sp. tritici race CYR32 were used throughout this study. Plants were grown, inoculated and exposed to different temperatures based on previously published protocols (Wang et al. 2017a).

For hormone and hydrogen peroxide treatments, 14-day-old wheat seedlings were sprayed with $100 \mu \mathrm{M} \mathrm{SA}, 100 \mu \mathrm{M}$ MeJA, $100 \mu \mathrm{M}$ ET, $100 \mu \mathrm{M} \mathrm{H}_{2} \mathrm{O}_{2}$, and $100 \mu \mathrm{M}$ ABA (Zhang et al.
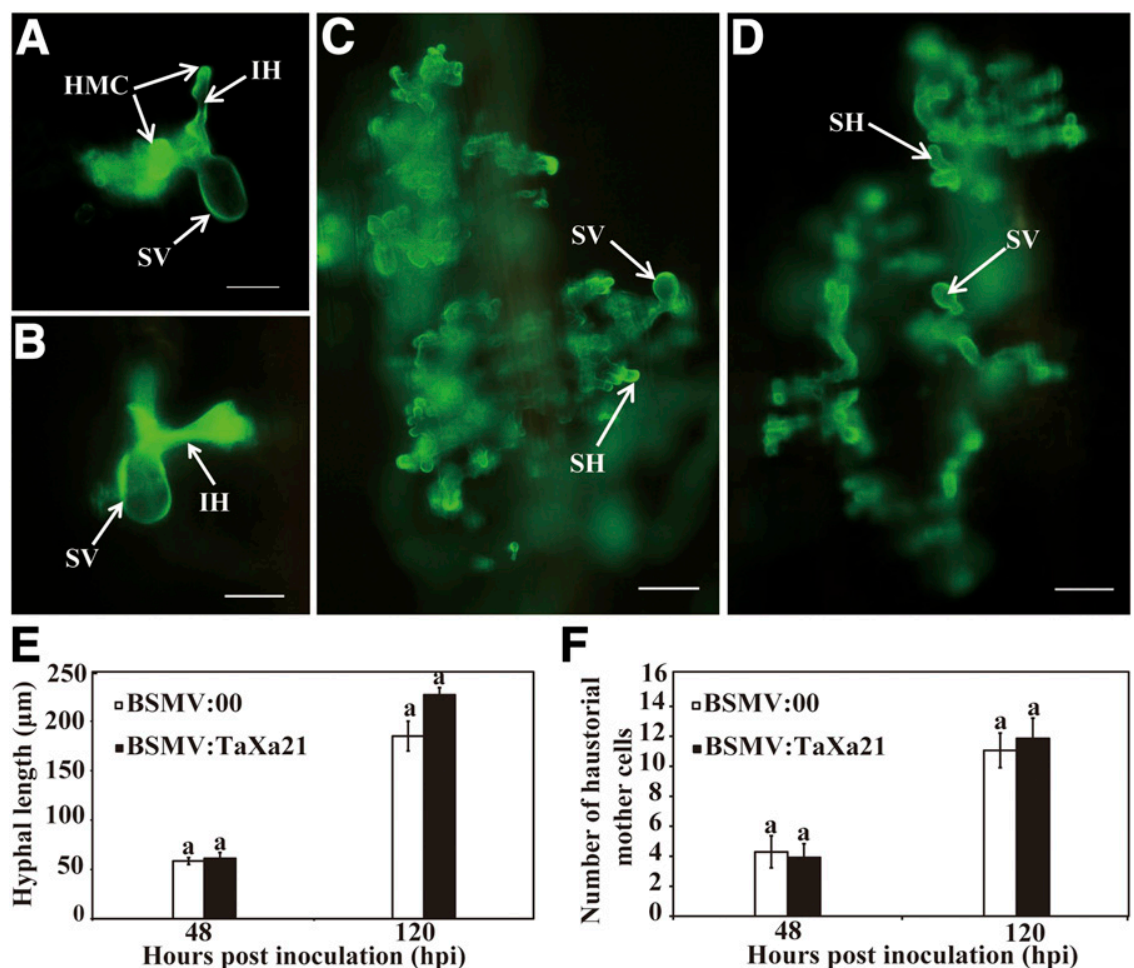

Fig. 4. Histological observation of fungal growth and host response in wheat leaves treated with barley stripe mosaic virus (BSMV) and inoculated with race CYR32 of Puccinia striiformis $\mathrm{f}$. sp. tritici strain under normal temperature (NT). A through D, The fourth wheat leaves were challenged with $P$. striiformis $\mathrm{f}$. sp. tritici in BSMV:00- (A and C) and BSMV: TaXa21-as (B and D)-inoculated leaves. Photographs were taken under an epifluorescent microscope at $48 \mathrm{~h}$ postinoculation (hpi) with $P$. striiformis f. sp. tritici. Bars $=20 \mu \mathrm{m}$ (A and B) and, at $120 \mathrm{hpi}, 50 \mu \mathrm{m}(\mathrm{C}$ and D). SV $=$ substomatal vesicle, IH = initial hyphae, HMC = haustorial mother cell. E, Hyphal length and F, number of haustorial mother cells in wheat leaves treated with BSMV and inoculated with race CYR32 of $P$. striiformis f. sp. tritici at 48 and 120 hpi under NT. Hyphal length in the average distance from the junction of the substomatal vesicle and the hyphal tip. Mean values and standard error were calculated from three replicates. Duncan's test was conducted among treatments at the same timepoint. There were no significant differences between each treatment at the same timepoint if they shared at least one common lowercase letter, on the basis of the Duncan's multiple range test.

Vol. 32, No. 11, $2019 / 1531$ 
2004) and were sampled at $0,0.5,2,6,12$, and 24 hpi ( 0 hpi: just before treatment). All chemicals were dissolved in $0.1 \%$ ( vol/vol) ethanol. The mock seedlings were treated with $0.1 \%$ (vol/vol) ethanol solution. The mean expression values of TaXa21 at 0 hpi for each treatment were converted to 1 to normalize the expression values of the same genes at the other timepoints for comparison. For tissue-specific expression analysis of $T a X a 21$, roots, stems, and leaves were sampled at the two-leaf stage. All samples were frozen in liquid nitrogen and stored at $-80^{\circ} \mathrm{C}$ for RNA extraction. For every sampling point, there were three biological replicates.

To evaluate the expression levels of TaXa21 in HTSP resistance to $P$. striiformis f. sp. tritici, wheat leaves were harvested at $0,48,96,192,194,198,204,216,240,264$, and $312 \mathrm{hpi}$ (HT was applied at $192 \mathrm{hpi}$ for $24 \mathrm{~h}$ ). Plants allocated to the mock-inoculation control were inoculated with sterile water. There were three biological replicates for each treatment at each sampling timepoint.

Identification and sequence analysis of TaXa21.

Based on transcriptome sequences, RACE primers (Supplementary Table S1) were designed to clone the $5^{\prime}$ and $3^{\prime}$ terminal sequences of $T a X a 21$. Amplification of cDNA ends was performed using the SMART RACE cDNA amplification kit
(Clontech). Specific primers were designed to obtain the full length of TaXa21, TaXa21-F, and TaXa21-R. The PCR product was cloned into the PMD18-T vector (TaKaRa, Tokyo) for sequencing. Protein molecular weight and PI were predicted with the DNAMAN6.0 software.

\section{RNA isolation and qRT-PCR.}

Total RNA from leaves of each sample was extracted using the SV total RNA isolation system (Promega) following manufacturer instructions. Total RNA (1,000 ng) was subjected to firststand cDNA synthesis with the PrimeScript RT reaction system (TaKaRa). qRT-PCR was performed to quantify TaXa21 expression, using UltraSYBR mixture (Kangwei, Beijing) in a volume of $25 \mu$; the Ta26s gene (ATP-dependent 26 s proteasome regulatory subunit) (Unigene number Ta22845) was used as an internal reference. Relative transcript levels of TaXa21 were calculated by the comparative cycle threshold $\left(2^{-\Delta \Delta \mathrm{Ct}}\right)$ method. The expression level was assessed from three replicates.

\section{BSMV-mediated TaXa21 silencing.}

A specific 151-bp cDNA was amplified with primers containing the NotI and PacI restriction enzyme sites and was inserted into the BSMV:r vector to form recombinant plasmid BSMV:TaXa21-as. Transcription in vitro was conducted using
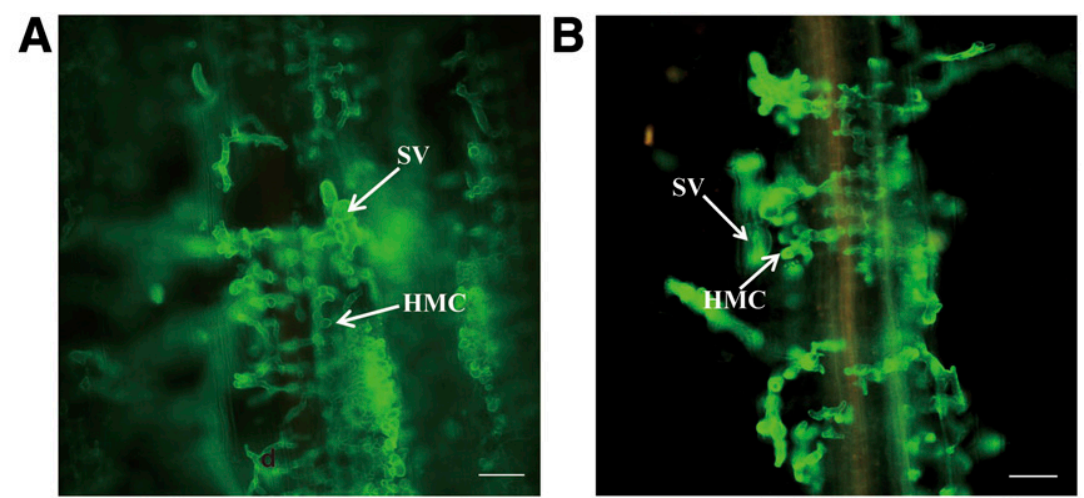

C

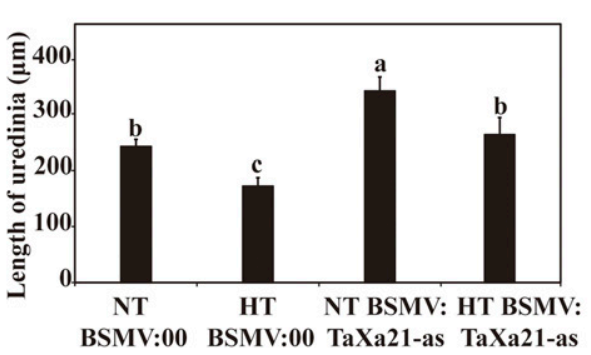

120 hours post temperature treatment

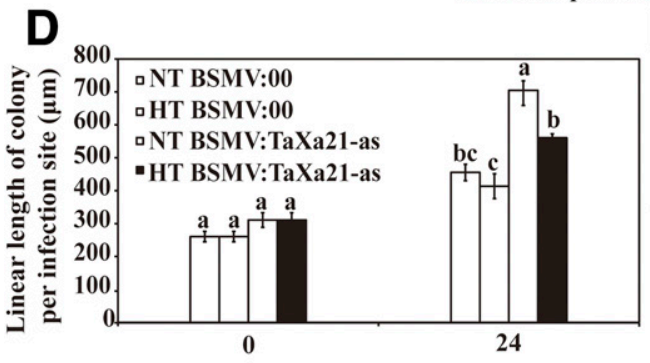

Hours post temperature treatment (hptt)

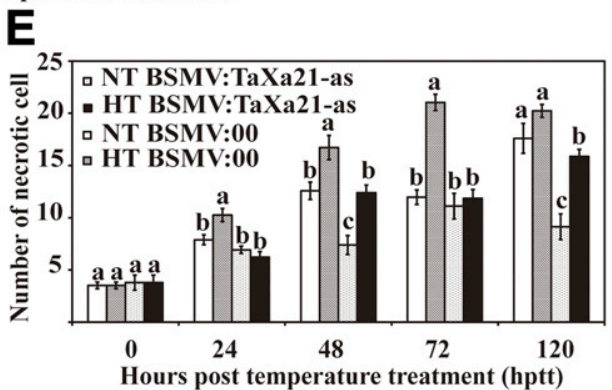

Fig. 5. Histological observation of race CYR32 of Puccinia striiformis f. sp. tritici development and wheat response in the TaXa21-silenced and control leaves leaves under A, normal temperature (NT) and B, high temperature (HT) during the initial symptom expression stage of $P$. striiformis f. sp. tritici development. Photographs were taken under an epifluorescent microscope. SV = substomatal vesicle, $\mathrm{HMC}=$ haustorial mother cell. Bars $=50 \mu \mathrm{m}$. $\mathbf{C}$, Uredinium length, $\mathbf{D}$, linear length of colony per infection sites and $\mathbf{E}$, numbers of necrotic cells were all recorded from 30 to 50 infection sites. Mean values and standard error were calculated from three replicates. Duncan's test was conducted among treatments at the same timepoint. There were no significant differences between treatments at the same timepoint if they share at least one common lowercase letter, on the basis of the Duncan's multiple range test. 
linearized products of $\alpha, \beta, \gamma, \gamma$-PDS (phytoene desaturase) or $\gamma$-TaXa21 as a template. BSMV virus vectors $(\alpha, \beta$, and $\gamma)$ or BSMV recombinant virus vectors $(\alpha, \beta, \gamma$-PDS, and $\alpha, \beta$, and $\gamma$-TaXa21) were inoculated onto the second leaves of wheat seedlings. Seedlings inoculated with BSMV: $\gamma$ and BSMV:PDS were used as negative and positive controls, respectively. The control plants were inoculated with $1 \times$ FES buffer $(0.1 \mathrm{M}$ glycine, $0.06 \mathrm{M} \mathrm{K}_{2} \mathrm{HPO}_{4}, 1 \%$ (wt/vol) tetrasodium pyrophosphate, $1 \%$ [wt/vol] bentonite, and $1 \%$ [wt/vol] celite, $\mathrm{pH} 8.5$ ). After inoculation, seedlings were kept at $25^{\circ} \mathrm{C}$ in the dark for $24 \mathrm{~h}$ and were subsequently maintained in a growth chamber at $25 \pm 1{ }^{\circ} \mathrm{C}$ with a 16 -h photoperiod. The fourth leaves with BSMV-inoculated were inoculated with $P$. striiformis f. sp. tritici CYR32, and seedlings were then maintained at $16 \pm 1^{\circ} \mathrm{C}$. P. striiformis f. sp. tritici development was assessed 14 dpi. For estimation of silencing efficiency of TaXa21, leaves inoculated with CYR32 were collected at 0, 24, 48, and 120 hpi and the expression level of $\mathrm{TaXa} 21$ was quantified.

\section{Determine the effect of HT on expression of TaXa21.}

To determine the effect of HT on TaXa21 expression in TaXa21silenced seedlings, two temperature treatments were applied to seedlings (including both TaXa21 nonsilenced and silenced seedlings): i) for the HT treatment, seedlings were exposed to $20^{\circ} \mathrm{C}$ at 8 dpi for $24 \mathrm{~h}$ (the late incubation stage of $P$. striiformis $\mathrm{f}$. $\mathrm{sp}$. tritici) and were then maintained at $15^{\circ} \mathrm{C}$; ii) for the continuous NT treatment, seedlings were maintained at $15^{\circ} \mathrm{C}$ all the time. Leaves from seedlings subjected to HT or NT treatments were sampled at $0,12,24,48,72$, and $120 \mathrm{hptt}$ to determine the transcript level of TaXa21 (0 hptt is the starting point of HT treatment). In addition, expression levels of two selected genes ( $\mathrm{TaCAT}$ and $\mathrm{TaACO}$ ) in the $\mathrm{H}_{2} \mathrm{O}_{2}$ and ET signaling pathways were quantified at $0,12,24,48$, 72 , and $120 \mathrm{hptt}$.

\section{Histological observation of $P$. striiformis f. sp. tritici development and wheat response.}

Wheat leaves were sampled at 48 and 120 hpi to measure hyphal length and estimate the number of haustorial mother cells. BSMV-treated leaves were sampled 0, 24, 48, 72, and 120 hptt for assessment of colony length, uredinium length, and the number of necrotic cells. Staining was performed following the method of Cheng et al. (2015). Hyphal length and the number of haustorial mother cells were determined under ultraviolet excitation with a fluorescent microscope. Cell death was assumed if autofluorescence was observed at the infection sites. For each treatment at each sampling timepoint, 30 to 50 infection sites from randomly chosen 8- to 10-leaf segments were randomly selected for assessment. The hyphal length, colony length, and uredinium length were estimated using the DPBSW software connecting to an Olympus BX51 microscope. Student's $t$ test was used to compare treatment effects at each timepoint, using SAS software (SAS Institute Inc.).

\section{Subcellular localization of TaXa21, TaWRKY76, and TaWRKY62.}

The full coding region of TaXa21, TaWRKY76, and TaWRKY62 without the stop codon was amplified with gene-specific primers and was cloned into the pCambia1302-GFP vector via NcoI and SpeI digestion, yielding pCambia-TaXa21-GFP, pCambia-TaWRKY76-GFP, and pCambia-TaWRKY62-GFP, respectively. Three recombination vectors and the control vector pCambia1302-GFP were transformed into Agrobacterium tumefaciens GV3101. Transformed A. tumefaciens cells containing recombination vector or pCambia1302-GFP were separately injected into the surface of tobacco leaves as previously described (Bracha-Drori et al. 2004). $\mathrm{H}_{2} \mathrm{~B}$-mcherry fusion and the PIP2A-mcherry fusion proteins were used as

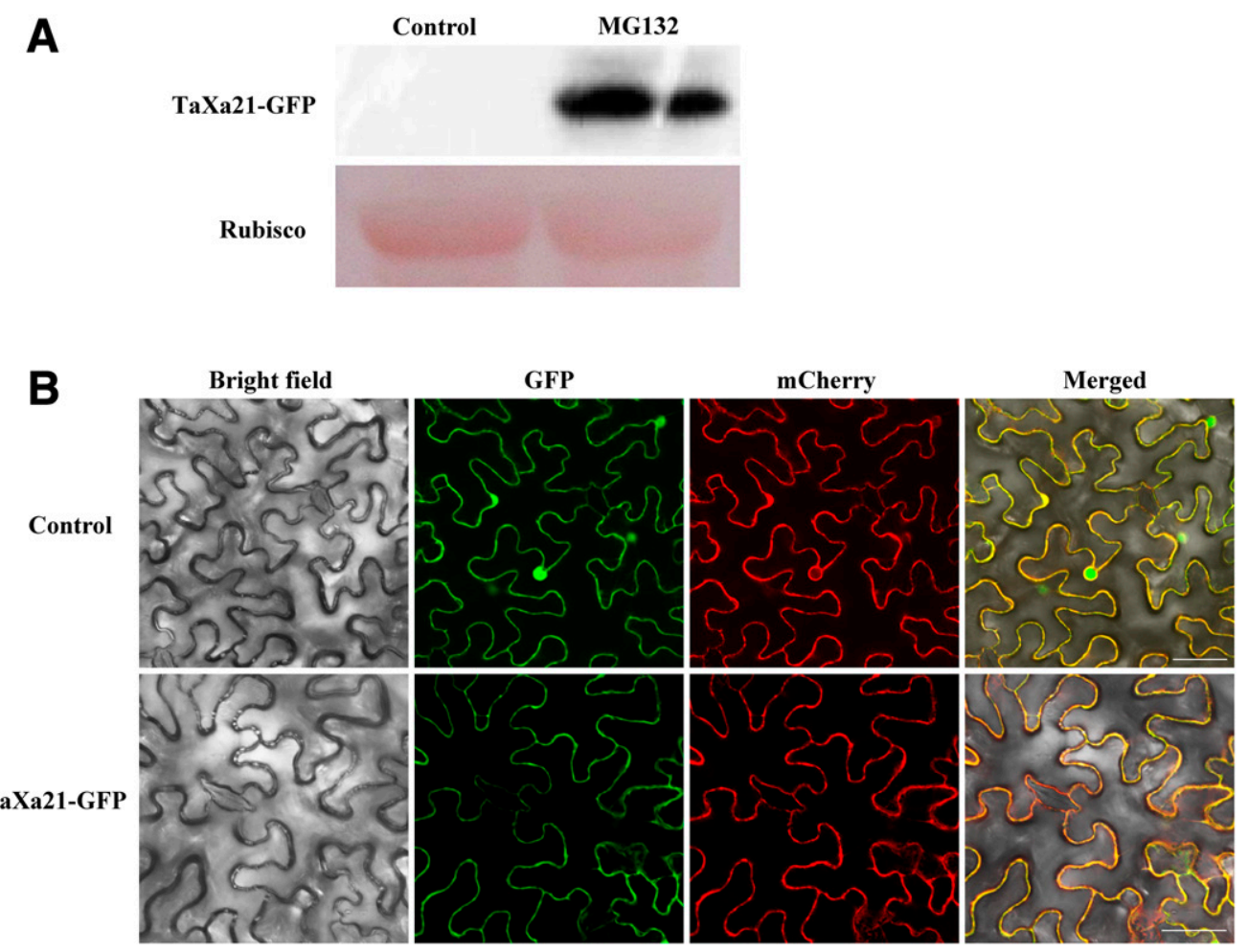

Fig. 6. Subcellular localization of TaXa21. A, TaXa21-GFP fusion protein expressed in tobacco (Nicotiana benthamiana) cells with (control) or without MG132 and detected by Western blot with Ponceau S staining. B, Images taken under a fluorescent microscope. Bright field represents the tobacco cells. Green fluorescent protein (GFP) (control) and TaXa21-GFP fusion protein were expressed in the tobacco cells, respectively. AtPIP2A protein, an aquaporin, was used as a plasma membrane location marker gene. Bar $=50 \mu \mathrm{m}$. Green fluorescence represents the location of GFP and TaXa21-GFP protein; red fluorescence represents the location of mcherry-AtPIP2A; bright field represents the tobacco cells; merge represents an overlap between green and red fluorescence. The large subunit of Rubisco was the loading control. 
nuclear and plasma membrane markers, respectively. Tobacco leaves were fully infiltrated with injection of $50 \mu \mathrm{M}$ MG132 at $12 \mathrm{~h}$ before sampling. The infiltrated tobacco leaves were observed under a fluorescent microscope within two to three days.

\section{Protein extraction and Western blot.}

Total protein was extracted from $500 \mathrm{mg}$ of tobacco leaves transformed with A. tumefaciens containing the pCambiaTaXa21-GFP vector with or without MG132 injection with $1 \mathrm{ml}$ of extraction buffer (50 mM Tris- $\mathrm{HCl}, \mathrm{pH} 7.5,150 \mathrm{mM} \mathrm{NaCl}$, $5 \mathrm{mM}$ EDTA, $3 \mathrm{mM}$ dithiothreitol, $0.5 \%$ Triton X-100, $1 \mathrm{mM}$ phenylmethylsulfonyl fluoride) and was separated by sodium dodecyl sulfate-polyacrylamide gel electrophoresis. GFP protein was detected with the anti-GFP antibody (Sigma). The large subunit of Rubisco was used as a loading control.

\section{Yeast two-hybrid.}

The bait and prey vectors were generated by inserting DNA fragments to pGBKT7 and pGADT7 plasmids, respectively. The transformed AH109 yeast cells harboring various combinations of bait and prey constructs were selected on SD medium lacking Leu and Trp and were then transferred to SD medium without Leu, Trp, and His to detect the selfactivation. Interaction was determined with yeast cells containing different plasmid combinations grown on SD medium without Leu, Trp, and His supplemented with $10 \mathrm{mmol} 3$-amino-1, 2, 4-triazole per liter, using a concentration selected based on the selfactivation test.

\section{Bimolecular fluorescence complementation assay.}

The TaXa21-F1, TaXa21-F2, and TaXa21-F3 segments were cloned with specific primers and were fused with $\mathrm{YFP}^{\mathrm{C}}$ to form TaXa21-F1-YFP ${ }^{\mathrm{C}}$, TaXa21-F2-YFP ${ }^{\mathrm{C}}$, and TaXa21-F3-YFP ${ }^{\mathrm{C}}$, respectively. The full-length coding sequences of TaWRKY76 and TaWRKY62 were cloned and fused with $\mathrm{YFP}^{\mathrm{N}}$ to form TaWRKY76-YFP ${ }^{\mathrm{N}}$ and TaWRKY62-YFP ${ }^{\mathrm{N}}$. The same method was used to construct TaWRKY62-YFPC .

The constructed plasmids were transformed into A. tumefaciens GV3101 cells and were then coinfiltrated into the leaves of 4-week-old tobacco plants in different combinations. YFP fluorescence was observed using a laser scanning microscope
A

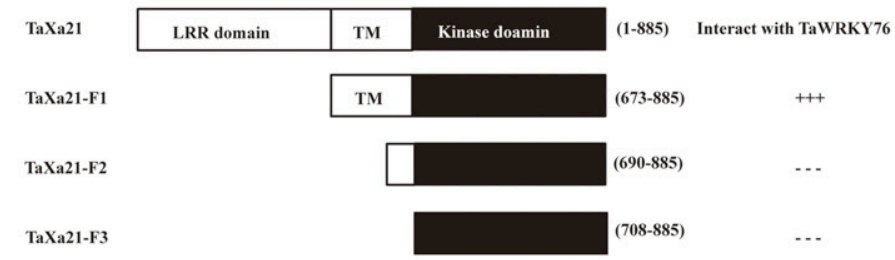

B

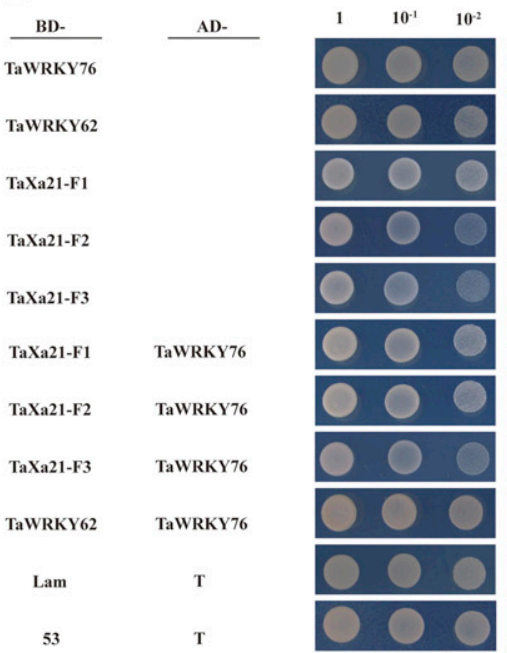

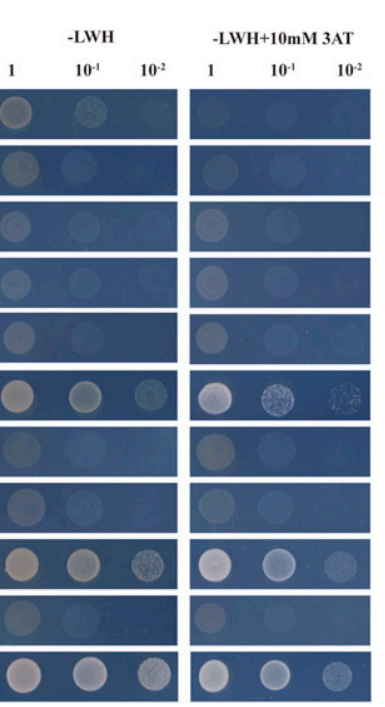

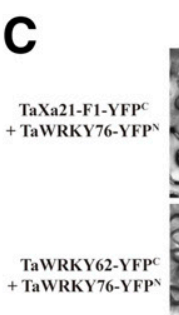

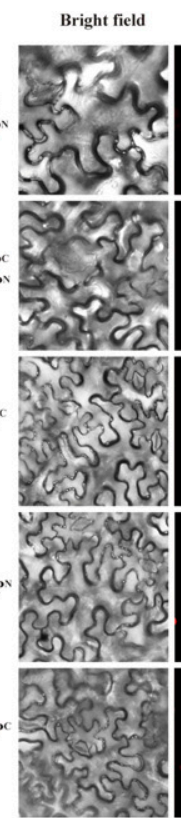

mCherry

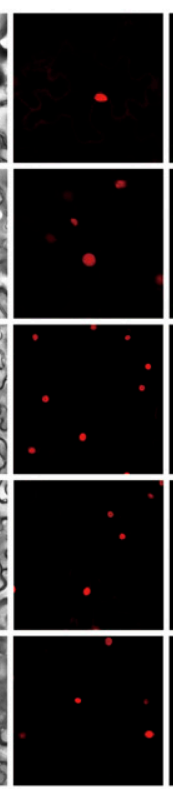

D

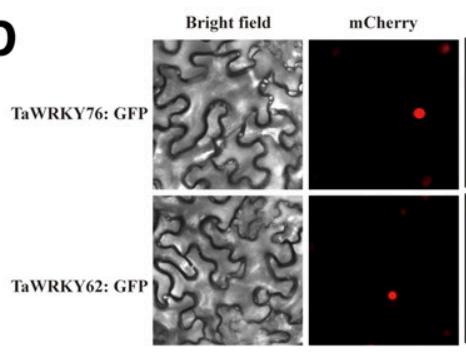

YFP
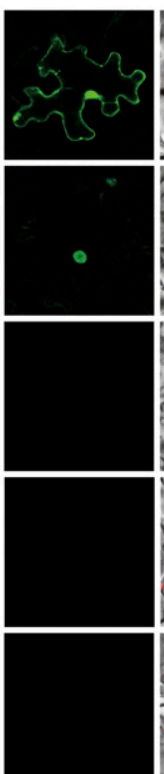

GFP

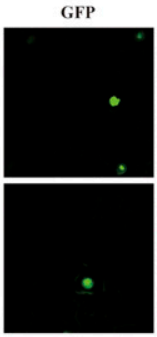

Merged

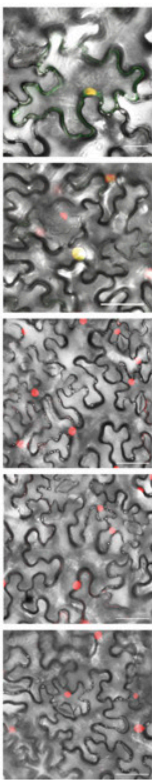

Merged

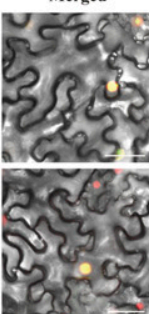

Fig. 7. Analysis of interaction among TaXa21, TaWRKY76, and TaWRKY62. A, Schematic diagrams of TaXa21-F1, TaXa21-F2, and TaXa21-F3, used in the analysis of interaction. B, Yeast two-hybrid assay. For autoactivation test, TaWRKY76, TaWRKY62, TaXa21-F1, TaXa21-F2, and TaXa21-F3 were fused with pGBKT7. For analysis of interaction, TaXa21-F1, TaXa21-F2, TaXa21-F3, and TaWRKY62 were fused with pGBKT7 to generate bait constructs; TaWRKY76 was fused with pGADT7 to generate prey construct. AH109 yeast cells with serial dilutions $\left(1,10^{-1}\right.$, and $\left.10^{-2}\right)$ were incubated in synthetic dropout medium lacking Leu and Trp (-LW), Leu, Trp, His (-LWH), or Leu, Trp, His (-LWH) supplemented with 10 mmol of 3-amino-1, 2, 4-triazole per liter. Yeast cells containing pGADT7-T and pGBKT7-53 or pGBKT7-Lam vectors were used as positive and negative control. C, Fluorescence complementation assay analysis of TaXa21 and TaWRKY76 and TaWRKY62 and TaWRKY76 interactions. TaXa21 and TaWRKY62 were fused with C-terminal domain of the yellow fluorescence protein (YFP). TaWRKY76 was fused with N-terminal domain of the YFP. The two different combinations of plasmids were transformed into the cells of tobacco (Nicotiana benthamiana). The images were taken 72 to $96 \mathrm{~h}$ after infiltration. AtH ${ }_{2} \mathrm{~B}$, a histone protein, was used as a nuclear location marker gene. The $\mathrm{AtH}_{2} \mathrm{~B}$-mcherry protein also shows red fluorescence in the nucleus. Merge shows an overlap between yellow and red fluorescence. The leaf cells of tobacco containing TaXa21-F1-YFP + YFP $^{\mathrm{N}}, \mathrm{YFP}^{\mathrm{C}}+\mathrm{TaWRKY76-YFP}$, and TaWRKY62-YFP $+\mathrm{YFP}^{\mathrm{N}}$ were used as negative controls. D, Subcellular localizations of TaWRKY76 and TaWRKY62. Tobacco (Nicotiana benthamiana) cells transformed with TaWRKY76-GFP and TaWRKY62-GFP fusion protein, respectively. Images were taken under an epifluorescent microscope. Bar $=50 \mu \mathrm{m}$. Merge shows an overlap between green and red fluorescence. 
(LECIA TCS SP8) three to four days later. The $\mathrm{H}_{2} \mathrm{~B}$-mcherry fusion protein was used as a nuclear marker.

\section{ACKNOWLEDGMENTS}

We thank X. Wang (Northwest A\&F University) for providing the BSMV vectors.

\section{AUTHOR-RECOMMENDED INTERNET RESOURCE}

IWGSC (International Wheat Genome Sequencing Consortium) database: http://www.wheatgenome.org/Tools-and-Resources/Wheat-TranscriptResources

\section{LITERATURE CITED}

Afzal, A. J., Wood, A. J., and Lightfoot, D. A. 2008. Plant receptor-like serine threonine kinases: Roles in signaling and plant defense. Mol Plant-Microbe Interact. 21:507-517.

Antolín-Llovera, M., Ried, M. K., Binder, A., and Parniske, M. 2012 Receptor kinase signaling pathways in plant-microbe interactions. Annu. Rev. Phytopathol. 50:451-473.

Bauer, Z., Gómez-Gómez, L., Boller, T., and Felix, G. 2001. Sensitivity of different ecotypes and mutants of Arabidopsis thaliana toward the bacterial elicitor flagellin correlates with the presence of receptor-binding sites. J. Biol. Chem. 276:45669-45676.

Bracha-Drori, K., Shichrur, K., Katz, A., Oliva, M., Angelovici, R., Yalovsky, S., and Ohad, N. 2004. Detection of protein-protein interactions in plants using bimolecular fluorescence complementation. Plant J. 40: 419-427.

Cantu, D., Yang, B., Ruan, R., Li, K., Menzo, V., Fu, D., Chern, M., Ronald, P. C., and Dubcovsky, J. 2013. Comparative analysis of protein-protein interactions in the defense response of rice and wheat. BMC Genomics $14: 166$.

Chae, L., Sudat, S., Dudoit, S., Zhu, T., and Luan, S. 2009. Diverse transcriptional programs associated with environmental stress and hormones in the Arabidopsis receptor-like kinase gene family. Mol. Plant 2:84-107.

Chen, X., Coram, T., Huang, X., Wang, M., and Dolezal, A. 2013. Understanding molecular mechanisms of durable and non-durable resistance to stripe rust in wheat using a transcriptomics approach. Curr. Genomics 14:111-126

Chen, X. M. 2005. Epidemiology and control of stripe rust [Puccinia striiformis f. sp tritici] on wheat. Can. J. Plant Pathol. 27:314-337.

Chen, X. M. 2007. Challenges and solutions for stripe rust control in the United States. Aust. J. Agric. Res. 58:648-655.

Chen, X. M. 2013. Review article: High-temperature adult-plant resistance, key for sustainable control of stripe rust. Am. J. Plant Sci. 4:608-627.

Chen, X. M., and Line, R. F. 1995. Gene action in wheat cultivars for durable, high-temperature, adult-plant resistance and interaction with race-specific, seedling resistance to Puccinia striiformis. Phytopathology 85:567-572.

Cheng, Y., Wang, X., Yao, J., Voegele, R. T., Zhang, Y., Wang, W., Huang, L., and Kang, Z. 2015. Characterization of protein kinase PsSRPKL, a novel pathogenicity factor in the wheat stripe rust fungus. Environ. Microbiol. 17:2601-2617.

Chisholm, S. T., Coaker, G., Day, B., and Staskawicz, B. J. 2006. Hostmicrobe interactions: Shaping the evolution of the plant immune response. Cell 124:803-814.

Dardick, C., Schwessinger, B., and Ronald, P. 2012. Non-arginine-aspartate (non-RD) kinases are associated with innate immune receptors that recognize conserved microbial signatures. Curr. Opin. Plant Biol. 15: 358-366.

Darnell, J. E., Jr., Kerr, I. M., and Stark, G. R. 1994. Jak-STAT pathways and transcriptional activation in response to IFNs and other extracellular signaling proteins. Science 264:1415-1421.

Gish, L. A., and Clark, S. E. 2011. The RLK/Pelle family of kinases. Plant J. 66:117-127.

Kim, T. W., and Wang, Z. Y. 2010. Brassinosteroid signal transduction from receptor kinases to transcription factors. Annu. Rev. Plant Biol. 61: 681-704.

Kinoshita, A., Betsuyaku, S., Osakabe, Y., Mizuno, S., Nagawa, S., Stahl, Y., Simon, R., Yamaguchi-Shinozaki, K., Fukuda, H., and Sawa, S. 2010. $R P K 2$ is an essential receptor-like kinase that transmits the CLV3 signal in Arabidopsis. Development 137:3911-3920.
Ma, Q., and Shang, H. S. 2000. High-temperature resistance of wheat cultivar Xiaoyan series to wheat stripe rust. Acta Agric. BorealiOccidentalis Sin. 9:39-42.

Morillo, S. A., and Tax, F. E. 2006. Functional analysis of receptor-like kinases in monocots and dicots. Curr. Opin. Plant Biol. 9:460-469.

Osakabe, Y., Yamaguchi-Shinozaki, K., Shinozaki, K., and Tran, L. S. 2013. Sensing the environment: Key roles of membrane-localized kinases in plant perception and response to abiotic stress. J. Exp. Bot. 64:445-458.

Peng, J. H., Fahima, T., Röder, M. S., Li, Y. C., Dahan, A., Grama, A., Ronin, Y. I., Korol, A. B., and Nevo, E. 1999. Microsatellite tagging of the stripe-rust resistance gene $\mathrm{YrH} 52$ derived from wild emmer wheat, Triticum dicoccoides, and suggestive negative crossover interference on chromosome 1B. Theor. Appl. Genet. 98:862-872.

Peng, Y., Bartley, L. E., Chen, X., Dardick, C., Chern, M., Ruan, R., Canlas, P. E., and Ronald, P. C. 2008. OsWRKY62 is a negative regulator of basal and Xa21-mediated defense against Xanthomonas oryzae pv. oryzae in rice. Mol. Plant 1:446-458.

Pruitt, R. N., Schwessinger, B., Joe, A., Thomas, N., Liu, F., Albert, M., Robinson, M. R., Chan, L. J. G., Luu, D. D., Chen, H., Bahar, O., Daudi, A., De Vleesschauwer, D., Caddell, D., Zhang, W., Zhao, X., Li, X., Heazlewood, J. L., Ruan, D., Majumder, D., Chern, M., Kalbacher, H., Midha, S., Patil, P. B., Sonti, R. V., Petzold, C. J., Liu, C. C., Brodbelt, J. S., Felix, G., and Ronald, P. C. 2015. The rice immune receptor XA21 recognizes a tyrosine-sulfated protein from a Gram-negative bacterium. Sci. Adv. 1:e1500245.

Rodriguez, M. C. S., Petersen, M., and Mundy, J. 2010. Mitogenactivated protein kinase signaling in plants. Annu. Rev. Plant Biol. 61:621-649.

Schoonbeek, H. J., Wang, H. H., Stefanato, F. L., Craze, M., Bowden, S. Wallington, E., Zipfel, C., and Ridout, C. J. 2015. Arabidopsis EF-Tu receptor enhances bacterial disease resistance in transgenic wheat. New Phytol. 206:606-613.

Shen, Q. H., Saijo, Y., Mauch, S., Biskup, C., Bieri, S., Keller, B., Seki, H., Ulker, B., Somssich, I. E., and Schulze-Lefert, P. 2007. Nuclear activity of MLA immune receptors links isolate-specific and basal diseaseresistance responses. Science 315:1098-1103.

Shiu, S. H., and Bleecker, A. B. 2001. Plant receptor-like kinase gene family: Diversity, function, and signaling. Sci. STKE 2001:re22.

Shpak, E. D., McAbee, J. M., Pillitteri, L. J., and Torii, K. U. 2005. Stomatal patterning and differentiation by synergistic interactions of receptor kinases. Science 309:290-293.

Sui, X. X., Wang, M. N., and Chen, X. M. 2009. Molecular mapping of a stripe rust resistance gene in spring wheat cultivar Zak. Phytopathology 99:1209-1215.

Tang, D., Wang, G., and Zhou, J. M. 2017. Receptor kinases in plantpathogen interactions: More than pattern recognition. Plant Cell 29: 618-637.

Tao, F., Wang, J., Guo, Z., Hu, J., Xu, X., Yang, J., Chen, X., and Hu, X. 2018. Transcriptomic analysis reveal the molecular mechanisms of wheat higher-temperature seedling-plant resistance to Puccinia striiformis f. sp. tritici. Front. Plant Sci. 9:240.

ten Hove, C. A., Bochdanovits, Z., Jansweijer, V. M., Koning, F. G., Berke, L., Sanchez-Perez, G. F., Scheres, B., and Heidstra, R. 2011. Probing the roles of LRR RLK genes in Arabidopsis thaliana roots using a custom TDNA insertion set. Plant Mol. Biol. 76:69-83.

Wang, J., Tao, F., An, F., Zou, Y., Tian, W., Chen, X., Xu, X., and Hu, X. 2017a. Wheat transcription factor TaWRKY7O is positively involved in high-temperature seedling plant resistance to Puccinia striiformis $\mathrm{f}$. $\mathrm{sp}$. tritici. Mol. Plant Pathol. 18:649-661.

Wang, J., Tao, F., Tian, W., Guo, Z., Chen, X., Xu, X., Shang, H., and Hu, X. 2017b. The wheat WRKY transcription factors TaWRKY49 and TaWRKY62 confer differential high-temperature seedling-plant resistance to Puccinia striiformis f. sp. tritici. PLoS One 12:e0181963.

$\mathrm{Xu}, \mathrm{X}$., Chen, C., Fan, B., and Chen, Z. 2006. Physical and functional interactions between pathogen-induced Arabidopsis WRKY18, WRKY40, and WRKY60 transcription factors. Plant Cell 18:1310-1326.

Zhang, Z. J., Yang, G. H., Li, G. H., Jin, S. L., and Yang, X. B. 2001 Transgressive segregation, heritability, and number of genes controlling durable resistance to stripe rust in one Chinese and two Italian wheat cultivars. Phytopathology 91:680-686.

Zhang, Z. L., Xie, Z., Zou, X., Casaretto, J., Ho, T. H., and Shen, Q. J. 2004 A rice WRKY gene encodes a transcriptional repressor of the gibberellin signaling pathway in aleurone cells. Plant Physiol. 134:1500-1513.

Zipfel, C., Kunze, G., Chinchilla, D., Caniard, A., Jones, J. D., Boller, T., and Felix, G. 2006. Perception of the bacterial PAMP EF-Tu by the receptor EFR restricts Agrobacterium-mediated transformation. Cell 125:749-760. 